\title{
Mountain Building Triggered Late Cretaceous North American Megaherbivore Dinosaur Radiation
}

\author{
Terry A. Gates ${ }^{1,2 *}$, Albert Prieto-Márquez ${ }^{3}$, Lindsay E. Zanno ${ }^{2,4}$
}

1 Ohio University College of Osteopathic Medicine, Athens, Ohio, United States of America, 2 North Carolina State University, Raleigh, North Carolina, United States of America, 3 Bayerische Staatssammlung für Paläontologie und Geologie, Munich, Germany, 4 Nature Research Center, North Carolina Museum of Natural Sciences, Raleigh, North Carolina, United States of America

\begin{abstract}
Prior studies of Mesozoic biodiversity document a diversity peak for dinosaur species in the Campanian stage of the Late Cretaceous, yet have failed to provide explicit causal mechanisms. We provide evidence that a marked increase in North American dinosaur biodiversity can be attributed to dynamic orogenic episodes within the Western Interior Basin (WIB). Detailed fossil occurrences document an association between the shift from Sevier-style, latitudinally arrayed basins to smaller Laramide-style, longitudinally arrayed basins and a well substantiated decreased geographic range/increased taxonomic diversity of megaherbivorous dinosaur species. Dispersal-vicariance analysis demonstrates that the nearly identical biogeographic histories of the megaherbivorous dinosaur clades Ceratopsidae and Hadrosauridae are attributable to rapid diversification events within restricted basins and that isolation events are contemporaneous with known tectonic activity in the region. SYMmETREE analysis indicates that megaherbivorous dinosaur clades exhibited significant variation in diversification rates throughout the Late Cretaceous. Phylogenetic divergence estimates of fossil clades offer a new lower boundary on Laramide surficial deformation that precedes estimates based on sedimentological data alone.
\end{abstract}

Citation: Gates TA, Prieto-Márquez A, Zanno LE (2012) Mountain Building Triggered Late Cretaceous North American Megaherbivore Dinosaur Radiation. PLoS ONE 7(8): e42135. doi:10.1371/journal.pone.0042135

Editor: Peter Dodson, University of Pennsylvania, United States of America

Received March 12, 2012; Accepted July 2, 2012; Published August 2, 2012

Copyright: (C) 2012 Gates et al. This is an open-access article distributed under the terms of the Creative Commons Attribution License, which permits unrestricted use, distribution, and reproduction in any medium, provided the original author and source are credited.

Funding: The Alexander von Humboldt Foundation, the National Science Foundation (grant \#EAR0959029 presented to G. Erickson and M. Norell), the Ministry of Education and Science of Spain (CGL2005-07878-C02-01 grant presented to À. Galobart), and North Carolina State University provided funding. The funders had no role in study design, data collection and analysis, decision to publish, or preparation of the manuscript.

Competing Interests: The authors have declared that no competing interests exist.

*E-mail: terryagates@gmail.com

\section{Introduction}

Studies of dinosaur diversification and distribution are generally conducted from a global perspective [1-4] because poor stratigraphic resolution within individual continents has thus far prevented finer-scaled paleobiogeographical analyses. Yet, understanding the dynamics of dinosaurian evolution at the intracontinental scale is required to identify correlative factors that may have driven lineage diversification at more inclusive levels.

Key studies [5,6] have established the Late Cretaceous Western Interior Basin (WIB) of North America as the most detailed chronostratigraphic framework available worldwide for fine-scale intracontinental studies of dinosaur biostratigraphy and biogeography. To date, little work has been conducted investigating fine-scale patterns of Laramidian dinosaur biodiversity at the subclade level. Gates et al. [7] found that late Campanian (76$74 \mathrm{Ma}$ ) North American dinosaur species exhibited a more restricted geographic distribution than expected for vertebrates of large-body size [8]. This result contrasts with the more cosmopolitan biogeographic patterns of Maastrichtian dinosaurs [9]. Similarly, global dinosaur diversity has been estimated as higher during the Campanian relative to the Maastrichtian [1014], yet little substantial evidence has been presented documenting potential causal factors for changing biodiversity patterns.

Among Late Cretaceous dinosaurs, the megaherbivorous hadrosaurid (duck-billed) and ceratopsid (horned) dinosaur clades provide exemplary case studies for examining macroevolutionary patterns because these clades are the most species-rich and possess refined phylogenetic relationships unparalleled in stratigraphic and geographic controls [15-17].

Here, we test for factors associated with the Campanian biodiversity surge within the WIB of North America-specifically the effects of mountain uplift on megaherbivorous dinosaur net diversification-within the most detailed biostratigraphic and biogeographic framework yet compiled for megaherbivorous dinosaurs.

\section{Geological Context and Orogenic Speciation}

During much of the Late Cretaceous, an epeiric intercontinental seaway (KWIS) inundated the central portion of North America, splitting the landmass into two island continents, Appalachia to the east and Laramidia to the west. Laramidia was further bounded on the west by the Sevier Orogenic belt (Fig. 1A). The Cretaceous-Neogene Laramide orogeny produced the Rocky Mountains of western North America, which are major physiographic features dictating modern climatic regimes and biogeographic patterns in this region [18]. Uplift began when the subducting Farallon tectonic plate shifted from a deeper to a more shallow position. This shift ultimately moved tectonic stresses further into the continental interior [19-21], leading to the uplift of mountains east of the Sevier Orogenic Belt (Fig. 1B). During the Late Cretaceous, inception of Laramide tectonics altered the 

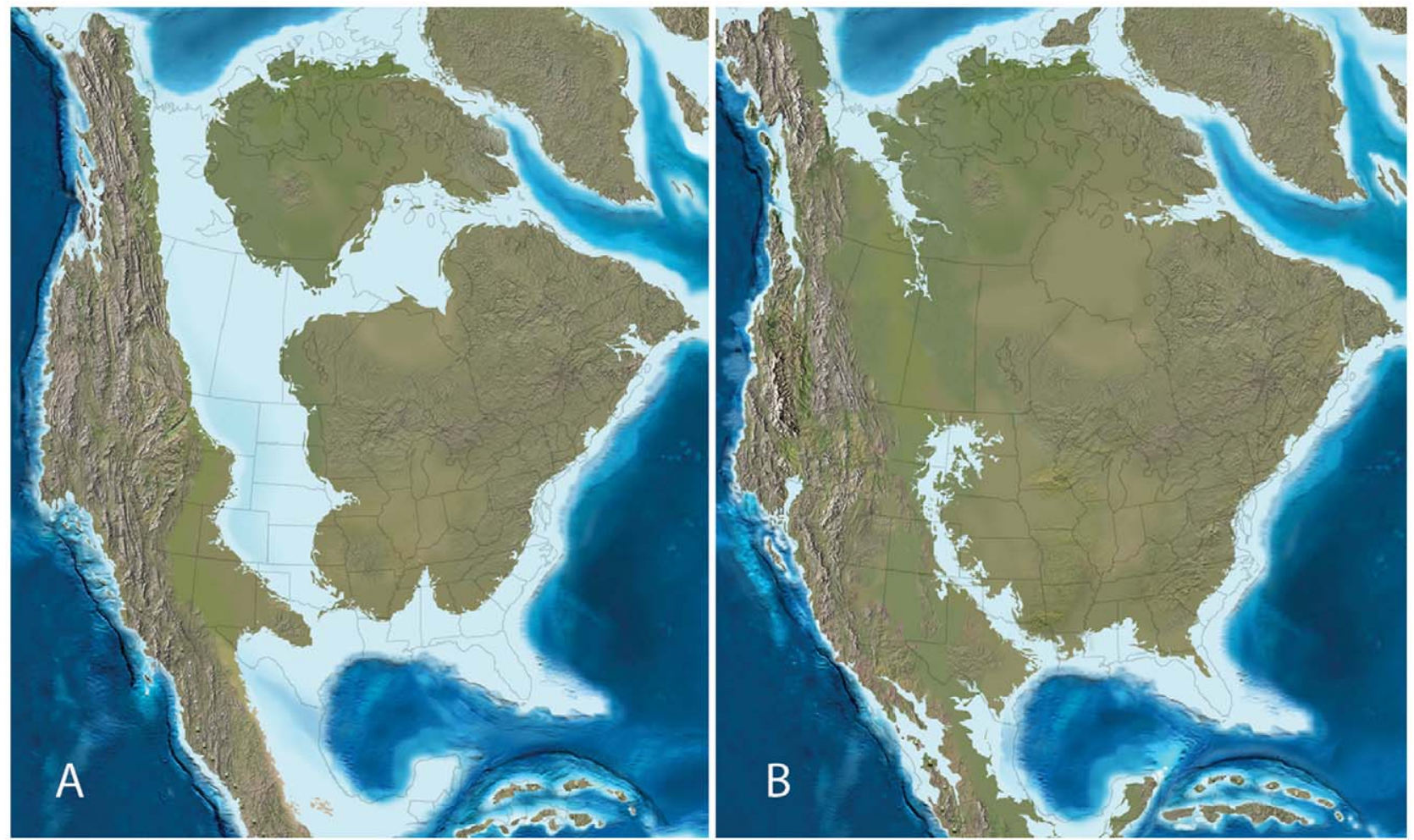

Figure 1. Paleogeographic maps of North America during the (A) late Campanian ( $75 \mathrm{Ma}$ ) and (B) late Maastrichtian ( $\sim 65 \mathrm{Ma})$. The Sevier Orogenic Belt is the major mountain building system in western North America during the late Campanian, but note that by the latest Maastrichtian the Laramide Orogeny creates uplift structures further to the east. Maps courtesy of Ron Blakey, Colorado Plateau Geosystems. doi:10.1371/journal.pone.0042135.g001

topography of the WIB from an extensive foreland basin into several smaller basins positioned east of the Sevier range and caused regression of the KWIS from its position in the center of North America at the close of the Campanian [22].

Varied techniques are utilized to date the onset of Laramide uplift. Isotopic ages from metamorphic or volcanic rocks provide a minimum time for the emplacement of uplifted structures $[23,24]$ and shifts in sedimentary basin drainage and subsidence allow relative dating of changes in drainage basin profile and source rock, which can be used to date emplacement of major topological alterations [5,20,22,25-29]. However, geologic evidence for uplift may be delayed relative to its earliest phases as a result of weathering and eroding uplifted rock, shifting river directions, and depositing subsequent sediments. Organismal evolution offers an independent line of evidence for the emplacement of major topographical features, which may prove useful in refining the timing of events substantiated by the geologic record. Refinement in the timing of uplift may be possible when biological evidence is taken into account because species are known to respond rapidly to environmental disturbance, with documented genetic differences appearing on the scale of mere decades [30].

Numerous studies have documented a relationship between orogenic activity and speciation rate [31-37]. These studies range from demonstrating changes associated with topographic complexity, proximity to orogenic centers, and coincidence of mountain uplift and phylogenetic patterns. For example, Miller and Mao [32] proposed that diversity of Ordovician invertebrate genera increased near orogenic centers. Peters [38] demonstrated that the macroevolutionary history of marine animals is driven by the creation and cessation of sedimentary basins regulated by eustatic and tectonic controls. Also, Finarelli and Badgley [37] showed that Miocene rodents occupying the Great Plains diversified at a slower rate than those living in the tectonically active Basin and Range province.

Several additional studies have focused on using evolutionary data to address the timing of orogenic events more specifically. For instance, Antonelli et al. [39] used the diversification pattern of South American coffee plants to corroborate geologic evidence of multiple episodes of Andean uplift. Likewise, Che et al. [36] used frog phylogenetics and environmental tolerance to time initial uplift of the Himalayan Mountains.

\section{Materials and Methods}

\section{Reconstruction of Ancestral Areas}

Ancestral areas for the clades recovered in the ceratopsid [40] and hadrosaurid [4] phylogenies were inferred via dispersalvicariance analysis (DIVA 1.1) [41] using the exact search according to the optimization algorithm of Ronquist [42]. DIVA is an event-based technique that integrates phylogenetic information with explicit models of the processes that shape the distribution of taxa [43]. The program assumes allopatric speciation due to vicariance as a null hypothesis; however, the method also considers dispersal and extinction as alternative processes influencing the resulting distribution of taxa. DIVA uses a model in which vicariance, sympatric speciation, dispersal, and extinction events are given different costs. These costs are inversely related to the likelihood of occurrence of these events [44]. Specifically, vicariance (speciation due to emergence of a dispersal barrier) and duplication (speciation within the same area) have a cost of zero, whereas dispersal and extinction events have a cost 
of one per each area unit added or deleted, respectively, from the distribution [42]. DIVA uses parsimony as optimality criterion and searches for the reconstruction that minimizes the number of dispersal-extinction events (or cost) required to explain the geographical distribution of terminal taxa [42]. This procedure is accomplished via optimization of a three-dimensional cost matrix, where the cost of an event depends on the combination of the distributions of the sister taxa descended from a common ancestor [42]. In order to allow for the possibility of widespread ancestors, the number of ancestral areas optimized for a particular node was left unrestricted. Node ages were derived from the literature. We considered the following discrete general areas in which these taxa have been recorded: Northern and Southern WIB of North America, Eastern North America, South America, Europe, and Asia.

\section{Diversification Rates}

The same phylogenetic trees utilized in DIVA were used to test for statistically significant variations in diversification rates in saurolophine hadrosaurids and chasmosaurine ceratopsids using the program SyMmeTREE version 1.0 [45]. This program implements topology-based techniques that allow for detection of significant variations in diversification among the lineages of a given phylogeny. It does so by comparing the observed topological distribution of the taxon diversity to the expectations according to an equal-rates model [45]. Furthermore, SymmeTREE incorporates the topological distribution of the diversity the taxa of the entire tree, as well as various tests that use information on the relative diversity of the internal nodes of the phylogeny [45].

\section{Results and Discussion}

Both hadrosaurids and ceratopsids demonstrate segregated evolutionary centers between approximately 76.0-75.5 million years, with subsequent integration of northern and southern faunas later in the Campanian and early Maastrichtian. Time calibrated phylogenies of these two groups provide compelling evidence for a north-south isolation event at approximately 79$78 \mathrm{Ma}$ (Figs. 2 and 3). Additionally, whole tree statistics from SymmeTREE analysis revealed that both saurolophines and chasmosaurines show significant variation in diversification rates $\left(p=4.1 \times 10^{-4}\right)$ throughout the Late Cretaceous (SymmeTREE Information S1). These results demonstrate dynamic rates of evolution in megaherbivores within the Campanian and Maastrichtian that are likely attributable to changing environmental factors.

\section{Hadrosaurid Campanian Biogeography}

Our DIVA analyses posit the most recent common ancestor of saurolophine hadrosaurids as inhabiting the Northern WIB no later than the early Campanian (Fig. 2). The occurrence of taxa from the Edmontosaurus-Gryposaurus clade of saurolophines can be explained by either vicariance of a widespread ancestor or dispersal from the Northern WIB to the Southern WIB, no later than the early Campanian. The major speciation events of North American taxa within both the Prosaurolophus and Gryposaurus subclades are unambiguously inferred to have been the result of vicariance during Campanian times.

The occurrence of Acristavus gagslarsoni in virtually coeval sediments (79.4, 79.3 Ma) from northwestern Montana and southern Utah [46] and Gryposaurus notabilis in both southern Alberta and southern Utah at approximately 76.5-76.0 Ma [17] demonstrates widespread distribution of saurolophine hadro- saurid dinosaurs throughout the early and middle Campanian (Fig. 4). At approximately $75.5 \mathrm{Ma}$, the geographic distribution of WIB hadrosaurids changes to one of localized species ranges. In southern Utah, a new species of Gryposaurus $-G$. monumentensisappears in the fossil record [47], while at the same time in Alberta the species Prosaurolophus maximus makes its first appearance $[15,48]$ (Fig. 4). These taxa are members of geographically isolated sister clades (Fig. 2), suggesting they diverged from a common ancestor and represent separate evolutionary centers of diversification. No species of hadrosaurid belonging to the northern Prosaurolophus clade is known from the southern WIB until 71.5-71.0 Ma [49].

Specimens of the Lambeosaurinae clade of hadrosaurid dinosaurs are much rarer in sediments older than $76 \mathrm{Ma}$ but a useful biogeographical pattern still is observable between 76 $73 \mathrm{Ma}$. The tube-crested lambeosaurine Parasaurolophus walkeri makes a rare appearance in the Dinosaur Park Formation of Alberta around $76 \mathrm{Ma}$, which occupies the lower megaherbivore faunal zone with its crested cohort Corythosaurus casuarius $[15,48,50]$. These two lambeosaurines resolve in separate clades (Fig. 5). Other species closely related to C. casuarius are known from the northern WIB until the mid-Maastrichtian [15,51,52], after which lambeosaurine hadrosaurids apparently go extinct in North America. To date, the only lambeosaurines known from the southern portion of the WIB confidently ranging between 76 $73 \mathrm{Ma}$ are Magnapaulia [52,53] and species of the genus Parasaurolophus. An unidentified species of this genus has been found within the Kaiparowits Formation dating from around $76 \mathrm{Ma}$ [17]; P. cyrtocristatus is known from the Fruitland Formation of northern New Mexico dated to approximately 74.5 Ma [54,55]; and finally $P$. tubicen is found in the Kirtland Formation of northern New Mexico in sediments aged 73.5 Ma [56]. The distributional pattern of Parasaurolophus could be easily achieved by a widespread distribution of the genus prior to 76 million years as concurrently observed in Saurolophinae taxa; however, no specimens are currently known from this time in the southern WIB to confirm this speculation.

\section{Ceratopsid Campanian Biogeography}

The subclade Chasmosaurinae has a broader known stratigraphic range (from the late Campanian to the terminal Maastrichtian) than its sister-clade Centrosaurinae [16] with species known from the interval 76-65 Ma. The ancestral area for Chasmosaurinae is posited through DIVA to be the Northern WIB during the Early Campanian (Fig. 3). Subsequently, a dispersal event into the Southern WIB led to a widespread ancestor of the most exclusive clade including Mojoceratops. A vicariance event occurring no later than the middle-late Campanian resulted in the northern isolation of the Mojoceratops lineage from the ancestor of the most exclusive clade including Agujaceratops, in the Southern WIB, which is indicative of two isolated evolutionary centers during the late Campanian $[16,40]$. The split of Kosmoceratops-Vagaceratops from the species-rich Maastrichtian Anchiceratops-Triceratops clade is inferred to have been the result of either a vicariance or dispersal event. Contrary to the smaller geographic ranges exhibited by chasmosaurines in the late Campanian, Maastrichtian species were wider ranging (e.g., Triceratops horridus [57]).

Centrosaurine ceratopsids have dominantly been recovered from sediments in Alberta and Montana, although a growing body of fossil data from southern Utah is providing information on the earliest Campanian stratigraphic distributions. Sampson and Loewen [16] describe the phylogenetic, geographic, and stratigraphic distribution of centrosaurines in detail; therefore, 


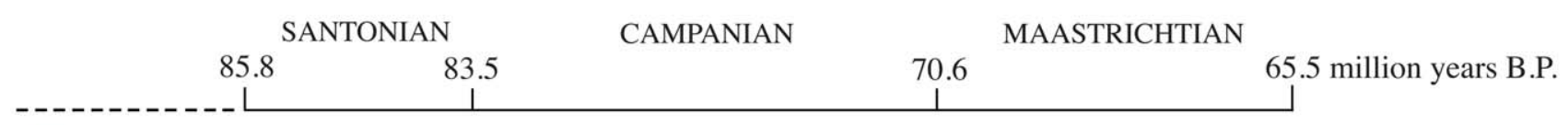

(96.5) Protohadros byrdi

(69) Telmatosaurus transsylvanicus

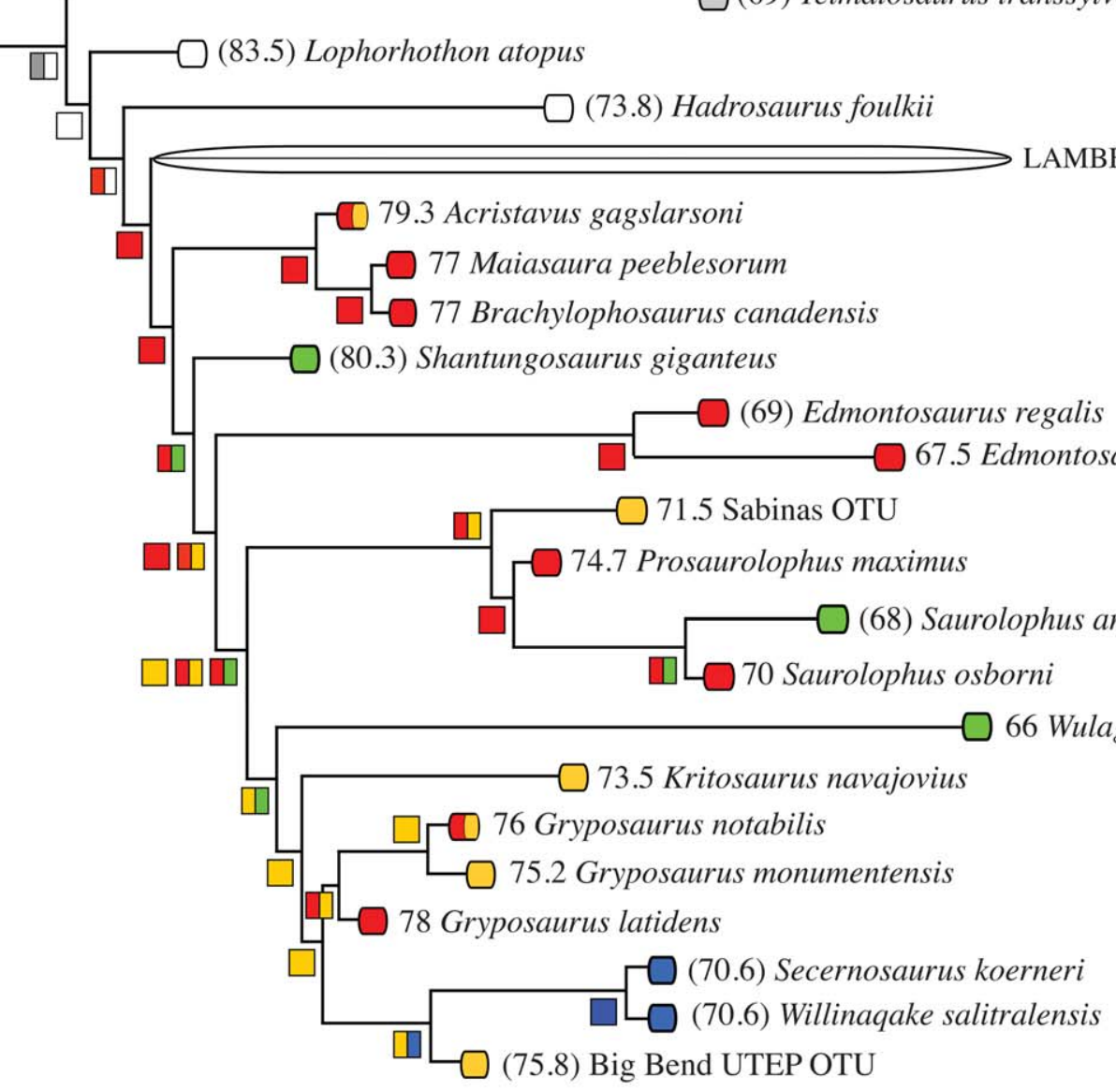
= Northern Western Interior Basin (North America)
$=$ Southern Western Interior Basin (North America)
$\square=$ Eastern North America
$=$ South America
$=$ Asia
$=$ Europe
$\oslash$ Europe + North America + Asia

Figure 2. Saurolophine hadrosaurid phylogeny from Prieto-Márquez [49] with taxa time calibrated to known geologic occurrences. Numbers in brackets indicate the midpoint of a geologic stage that a taxon is known to occur if that species does not have more constrained stratigraphic ages. Symbols on phylogenetic branches designate the inheritance of geographic distribution based on results from the DIVA analyses. doi:10.1371/journal.pone.0042135.g002

only information relating to this study will be presented. Centrosaurine taxa that occur in the early Campanian are found throughout the WIB, yet they are not co-occurring, and geographic distributions across large distances cannot be ascertained. However, around $75.5 \mathrm{Ma}$ a new species found in the Kaiparowits Formation is contemporaneous with Centrosaurus apertus in Alberta, although they are found in separate clades. This illustrates another example of isolated evolutionary centers at the same time as observed in chasmosaurine ceratopsids and both clades of hadrosaurids. The remainder of the centrosaurine data presented in Sampson and Loewen [16] does not contribute further information to this study.

\section{Onset of the Laramide Orogeny and Dinosaur \\ Cladogenesis}

Several recent studies have used the established connection between phylogenetic relationships and tectonic activity to better understand the relationship between evolutionary patterns, changing geography, and onset of orogenic events [32,36-39]. Our analyses on biogeography and diversification rates in megaherbivorous dinosaurs allow for independent testing of hypotheses regarding the timing and influence of Laramide tectonics.

Our combined analyses suggest that geographic and ecological barriers created from incipient Laramide uplift, in 


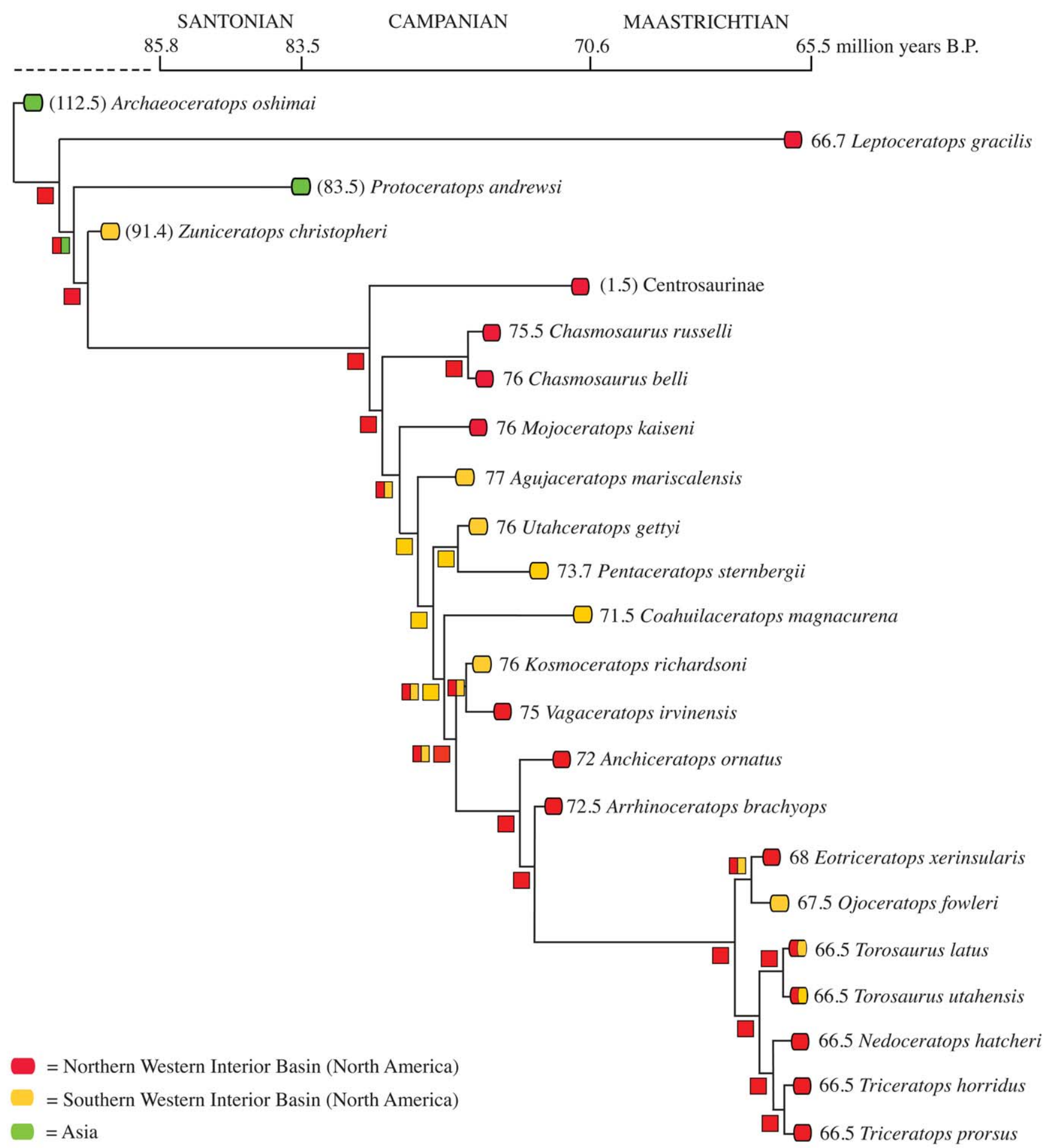

Figure 3. Chasmosaurine ceratopsid phylogeny from Sampson et al. [40] with taxa time calibrated to known geologic occurrences. Numbers in brackets indicate the midpoint of a geologic stage that a taxon is known to occur if that species does not have more constrained stratigraphic ages. Symbols on phylogenetic branches designate the inheritance of geographic distribution based on results from the DIVA analyses. Note that Torosaurus and Triceratops both appeared on the Sampson et al. [40] phylogeny used in this study; and that in light of recent work documenting these taxa as congeneric [68], they remain as distinct genera within the present figure in order to maintain the original data integrity of the Sampson et al. [40] study, but are considered and discussed here as solely Triceratops. doi:10.1371/journal.pone.0042135.g003

combination with the presence of the Sevier Orogenic Belt and the KWIS, caused initial isolation of northern and southern dinosaurs that ultimately led to the establishment of geographically restricted evolutionary centers. Several predictive tests of speciation via tectonic processes outlined by Badgley [35] can be applied to test this hypothesis: 1) increased levels of endemism should be present in regions affected by tectonic speciation, 2) speciation rates should be greater in topograph- 


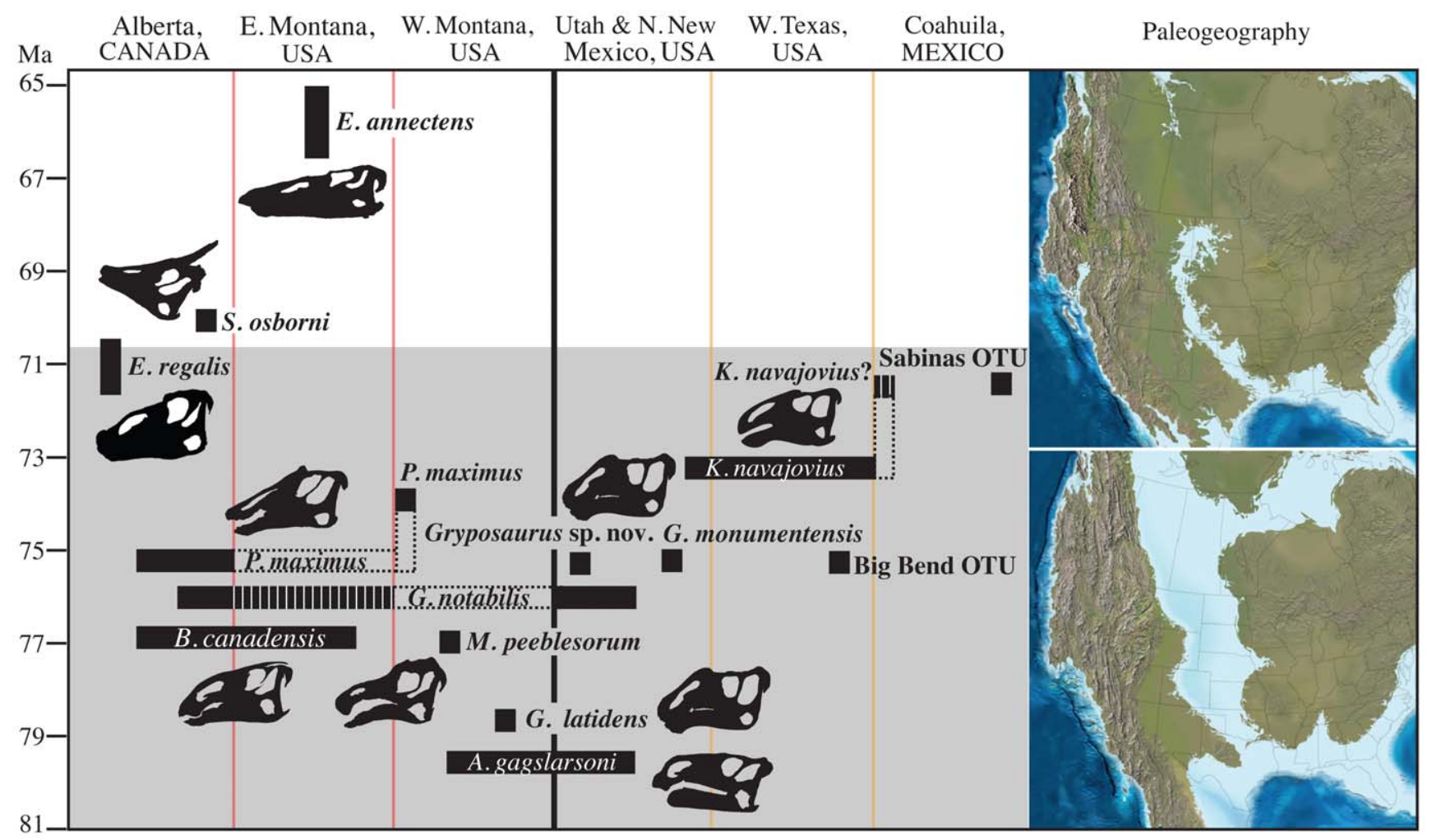

Figure 4. Saurolophine range distribution throughout the Western Interior Basin during the Campanian (lower grey area) and Maastrichtian (upper white area). To the right, paleogeographic maps of North America during the late Campanian ( $\sim 75 \mathrm{Ma})$ and late Maastrichtian ( $\sim 65 \mathrm{Ma})$. The sources for the geographic and stratigraphic position of the hadrosaurid species are as follows: Acristavus gagslarsoni [46], Brachylophosaurus Canadensis [81], Edmontosaurus annectens and E. regalis [82], Gryposaurus latidens [83], G. monumentensis [47], G. notabilis [15], Gryposaurus new species [84], Kritosaurus navajovius [85,86], Maiasaura peeblesorum [81], Prosaurolophus maximus [15,49], Sabinas OTU [4,49], Saurolophus osborni $[15,87]$, and UTEP OTU [49,88]. Maps courtesy of Ron Blakey, Colorado Plateau Geosystems. doi:10.1371/journal.pone.0042135.g004

ically complex regions, and 3) correspondence should exist between tectonic activity and cladogenesis.

Test 1: Tectonics and endemism. Our analyses demonstrate that hadrosaurid and ceratopsid endemism increases in the earliest stages of the Laramide uplift as defined by geologic evidence. DIVA results (Fig. 3) provide the first rigorous support for the hypothesis that chasmosaurine ceratopsids exhibited widespread geographic distributions throughout the WIB during the early Campanian [40]; additionally, this study is the first to demonstrate that hadrosaurids are also widespread during the early Campanian (Figs. 2 and 4). Subsequently (approximately $75.5 \mathrm{Ma}$ ), megaherbivore lineages exhibit more restricted ranges, appearing to have been isolated to either Montana-Alberta (Prosaurolophus, Chasmosaurus) or southern Utah (Gryposaurus monumentensis, Kosmoceratops, Utahceratops). Vicariance events during the middle and late Campanian are also supported by ancestral area reconstructions. Restricted endemism terminated during the Maastrichtian when the KWIS retreated allowing taxa to roam eastward and inhabit wider geographic ranges [9] (Figs. 2, 3, 4).

Development of more stringent climatic and ecologic regimes may have played an important role in the isolation of hadrosaurid and ceratopsid faunas in the late Campanian. Examples from the modern record [58-60] indicate that ecosystems alter in composition along with subtle variations in elevation incited by orogenic uplift. Although lower global temperature gradients may have mitigated this effect in the Campanian to some degree, changing topography in the WIB would undoubtedly have spurred changes in ecosystem composition. As Late Cretaceous orogenesis com- menced weather patterns that were previously dictated by Sevierinduced topography would begin to change because of newly introduced landforms, albeit small at first, which over time would rise to significant heights. Profoundly, changes in elevation would alter air currents and local climate regimes, which would have the compounding effect of changing annual temperatures and rainfall averages. Plant communities have been shown to be sensitive to subtle changes in altitude, rainfall, and humidity $[58,61,62]$ and these conditions ultimately dictate local plant composition. McLachlan et al. [63] found that trees migrate at a slower rate than previously appreciated. Therefore, the climatic changes periodically occurring as a result of orogenic uplift and basin segregation may have occurred sufficiently fast enough to outpace plants from crossing these barriers, and thereby altering ecosystems substantially enough to create isolated biomes. This hypothesis is supported by documented palynomorph evidence, which indicates isolated pollen provinces that have long been recognized in Late Cretaceous sediments [64]. Modified plant communities may have acted in combination with potential geographic barriers (such as the Castlegate river/delta system and Wind River Mountains) to spur ecological barriers [65] to herbivorous dinosaurs, preventing gene flow, and creating endemic centers of megaherbivorous dinosaur evolution.

Test 2: Late cretaceous diversification rates. SymmeTREE results clearly establish that hadrosaurids and ceratopsids experienced significant variations in diversification rates. If taxonomic diversity reflects net diversification rate, there exists higher diversification for Campanian hadrosaurids 


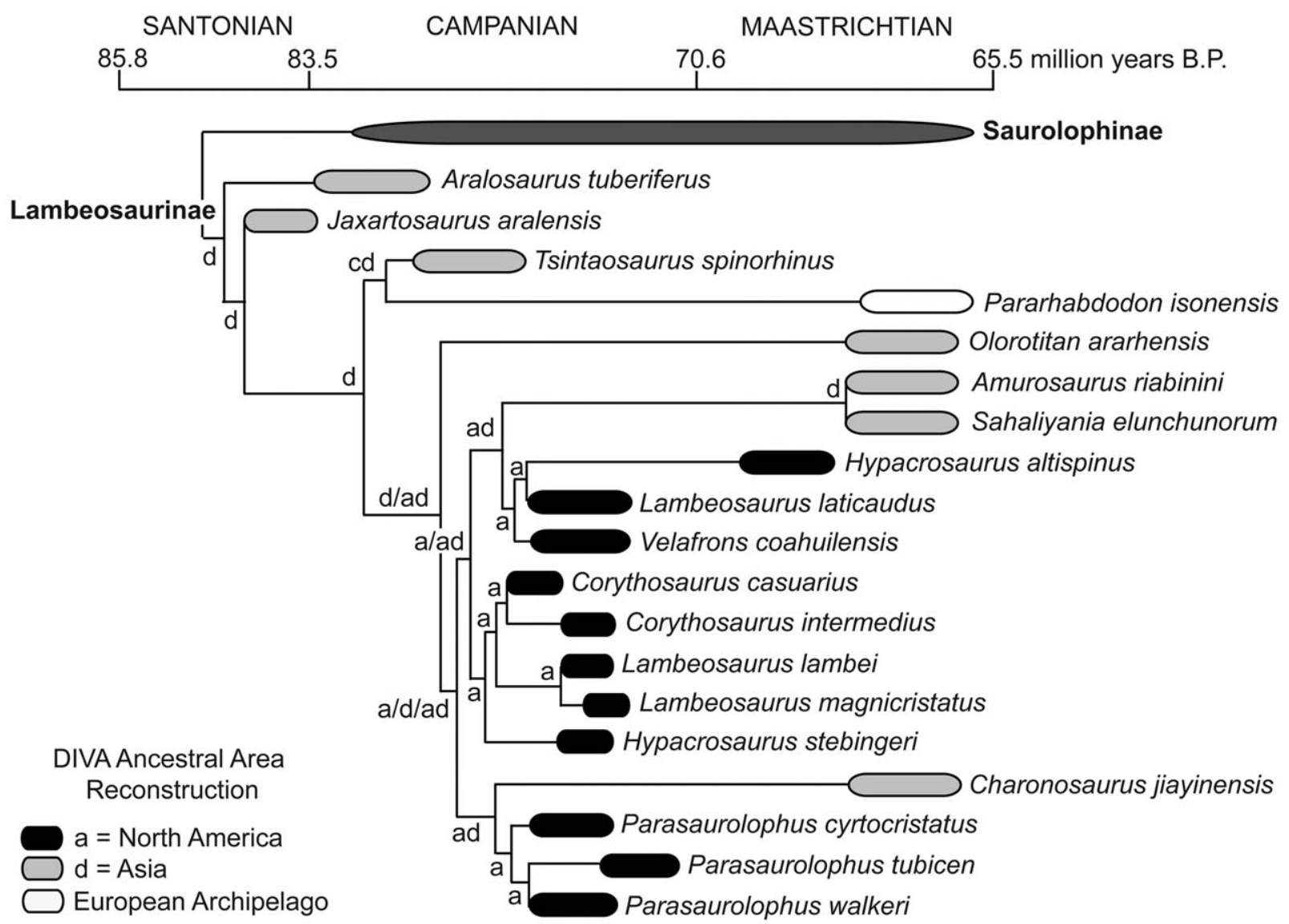

Figure 5. Time calibrated phylogeny of lambeosaurine hadrosaurids. Data from Prieto-Márquez et al. [52]. doi:10.1371/journal.pone.0042135.g005

and ceratopsids when compared to Maastrichtian rates. Our data show that in a small window of the Campanian when several topographic features (Sevier Orogenic Belt, KWIS, and Laramide structures) coincided, new megaherbivorous dinosaur species appeared at average rates of more than one species per million years, as opposed to the Maastrichtian rates of one species per several million years. If one compares the diversity in hadrosaurids and ceratopsids only in two formations within the northern region of the WIB, there is direct evidence of seven hadrosaurid taxa $[15,66]$ with additional ghost lineage evidence of two taxa, and direct evidence of at least five ceratopsids [16] found in the 1.5 Myr Dinosaur Park Formation with additional ghost lineage [67] evidence of one taxon, whereas evidence exists of only one hadrosaurid (Edmontosaurus regalis) and up to three ceratopsids (Triceratops horridus, T. prorsus and possibly Torosaurus latus) from the $1.37 \mathrm{Myr}$ Hell Creek Formation [68,69]. Even more dramatic is the evidence that during the entire 5 million year Maastrichtian stage preserved in the northern Western Interior Basin, there are only four hadrosaurids documented [66,70] (Hypacrosaurus altispinus, Saurolophus osborni, Edmontosaurus annectens, and E. regalis) with no ghost lineage additions, and three to five ceratopsids [16,68,71] (Eotriceratops, Nedoceratops, Torosaurus latus Triceratops prorsus, and $\mathcal{T}$. horridus), with up to five ghost lineage taxa. These data are not biased on sampling due to nearly 150 years of prospecting in both time periods, and greater outcrop area of the Maastrichtian strata. Additionally, Campione and Evans [70] found a plausible Maastrichtian drop in megaherbivore diversity based on morphological disparity. Therefore, net diversification rates slowed in correspondence with an increase in habitable land, as predicted.

Test 3: Tectonic correspondence. The phylogenetic and geographic range data for megaherbivorous dinosaurs support the hypothesis that the thrust of clade diversification is contemporaneous with the establishment of Laramide uplift between southern Alberta and southern Utah approximately 75 Ma. More specifically, the Wind River Mountains of southern Wyoming started cooling between 85-75 Ma [23], and the Big Horn Mountains began cooling as early as $70 \mathrm{Ma}$ [24]. The Rock Springs and Douglas Creek uplift initiated simultaneously in the Campanian [72]. Uplift of the Colorado Plateau reached two peaks of maximum ascension rate at approximately $80 \mathrm{Ma}$ and $70 \mathrm{Ma}$ [73]. Several drainage basins in southern Utah that date to approximately $74.5 \mathrm{Ma}$ show increased subsidence rates and changes to flow direction hypothesized to be part of the Laramide uplift [28,29]. The Castlegate river delta system deposited as a result of uplift of the Charleston-Nebo salient in the early Campanian [74] ( $\sim 7 \mathrm{Ma})$. Together, these data firmly establish a correspondence between the main thrust of dinosaur cladogenesis as documented by fossil evidence and establishment of incipient Laramide tectonic structures as evidenced by the geologic record. However, our phylogenetic analyses time the initial divergence of Chasmosaurus and Pentaceratops clade ceratopsids and Gryposaurus and Prosaurolophus clade hadrosaurids at approximately 78.5 Ma, suggesting that topographical surficial deformation caused by the Laramide orogeny may have been present in the 
early Campanian. This date precedes estimates based on substantial sedimentological evidence and, if plausible, provides the earliest evidence for the Laramide orogeny north of Arizona/New Mexico [75-78].

\section{Conclusion}

We provide quantitative evidence that rapid cladogenesis of Campanian megaherbivores occurred coincidentally with incipient confluence of the Sevier Orogenic Belt, KWIS, and Laramide tectonics, and that once the Laramide uplift was substantial enough to drive regression of the KWIS during the Maastrichtian, net diversification rates followed suit. Phylogenetic divergence estimates of fossil clades offer a new lower boundary on Laramide surficial deformation that precedes estimates based on sedimentological data alone.

Application of these results to other dinosaur groups contemporaneously living in Laramidia is an interesting prospect. The major hurdle to such comparative studies is insufficient fossil records of other clades, although based on limited data theropods may exhibit similar trends. Different species of tyrannosaurid and troodontid are known to live within the northern and southern WIB approximately 75.5 Ma [79,80]. Once established, comparison of the trends observed within ceratopsids and hadrosaurids in response to the unique geologic and topographic conditions

\section{References}

1. Sampson SD, Witmer LM, Forster CA, Krause DW, O'Connor PM, et al. (1998) Predatory dinosaur remains from Madagascar: implications for the Cretaceous biogeography of Gondwana. Science 280: 1048-1051.

2. Upchurch P, Hunn CA, Norman DB (2002) An analysis of dinosaurian biogeography: evidence for the existence of vicariance and dispersal patterns caused by geological events. Proceedings of the Royal Society of London B 269: 613-621.

3. Sereno PC, Wilson JA, Conrad JL (2004) New dinosaurs link southern landmasses in the mid-Cretaceous. Proceedings of the Royal Society of London, Series B 271: 1325-1330.

4. Prieto-Marquez A (2010) Global historical biogeography of hadrosaurid dinosaurs. Zoological Journal of the Linnean Society 159: 503-525.

5. Roberts EM, Deino AL, Chan MA $(2005){ }^{40} \mathrm{Ar} /{ }^{39} \mathrm{Ar}$ age of the Kaiparowits Formation, southern Utah, and correlation of contemporaneous Campanian strata and vertebrate faunas along the margin of the Western Interior Basin. Cretaceous Research 26: 307-318.

6. Jinnah ZA, Roberts EM, Deino AL, Larsen JS, Link PK, et al. (2009) New ${ }_{40} \mathrm{Ar}-{ }^{39} \mathrm{Ar}$ and detrital zircon U-Pb ages for the Upper Cretaceous Wahweap and Kaiparowits formations on the Kaiparowits Plateau, Utah: implications for regional correlation, provenance, and biostratigraphy. Cretaceous Research 30: 287-299.

7. Gates TA, Sampson SD, Zanno LE, Roberts EM, Eaton JG, et al. (2010) Biogeography of terrestrial and freshwater vertebrates from the late Cretaceous (Campanian) Western Interior of North America. Palaeogeography, Palaeoclimatology, Palaeoecology 291: 371-387.

8. Burness GP, Diamond J, Flannery T (2001) Dinosaurs, dragons, and dwarfs: The evolution of maximal body size. Proceedings of the National Academy of Sciences 98: 14518-14523.

9. Vavrek MJ, Larsson HCE (2010) Low beta diversity of Maastrichtian dinosaurs of North America. Proceedings of the National Academy of Science 107: 8265 8268.

10. Fastovsky DE, Huang Y, Hsu J, Martin-McNaughton J, Sheehan PM, et al. (2004) Shape of Mesozoic dinosaur richness. Geology 32: 877-880.

11. Barrett PM, McGowan AJ, Page V (2009) Dinosaur diversity and the rock record. Proceedings of the Royal Society B 276: 2667-2674.

12. Butler RJ, Benson RBJ, Carrano MT, Mannion PD, Upchurch P (2010) Sea level, dinosaur diversity and sampling biases: investigating the 'common cause' hypothesis in the terrestrial realm. Proceedings of the Royal Society B doi: $10.1098 / \mathrm{rspb} .2010 .1754$.

13. Dodson $P(1990)$ Counting dinosaurs: how many kinds were there? Proceedings of the National Academy of Sciences 87: 7608-7612.

14. Wang SC, Dodson P (2006) Estimating the diversity of dinosaurs. Proceedings of the National Academy of Science 103: 13601-13605.

15. Ryan M, Evans DC (2005) Ornithischian dinosaurs. In: Currie PJ, Koppelhus EB, editors. Dinosaur Provincial Park: A spectacular ancient ecosystem revealed. Indianapolis: Indiana University Press. 312-348.

16. Sampson SD, Loewen MA (2010) Unraveling a radiation: A review of the diversity, stratigraphic distribution, biogeography, and evolution of horned dinosaurs. In: Ryan MJ, Chinnery-Allgeier BJ, Eberth DA, editors. New spotlighted in this study to those trends observed in other dinosaur clades will allow insights into the tempo and modes of evolutionary change among the dominant terrestrial vertebrates of the Cretaceous.

\section{Supporting Information}

\section{SymmeTREE Information S1 Data output files from SYMMETREE analysis of ceratopsid and hadrosaurid phylogenies. (XLSX)}

\section{Acknowledgments}

We thank B. Rowe, T. Lawton, M. Hopkins, and D. Evans for discussions. S. Sampson for access to ceratopsid phylogeny. P. Makovicky, N. Smith, and S. Brusatte for analytic assistance. D. Evans, P. Dodson, U. Joger and an anonymous reviewer provided helpful comments that strengthened the paper. R. Blakey (Colorado Plateau Geosystems) graciously allowed use of paleobiogeographic maps.

\section{Author Contributions}

Conceived and designed the experiments: TAG AP-M LEZ. Performed the experiments: TAG AP-M. Analyzed the data: TAG AP-M LEZ. Wrote the paper: TAG AP-M LEZ.

perspectives on horned dinosaurs. Indianapolis, IN: Indiana University Press. 405-427.

17. Gates TA, Lund EK, Boyd CA, DeBlieux DD, Titus AL, et al. (in press) Ornithopod dinosaurs from the Grand Staircase-Escalante National Monument region, Utah and their role in paleobiogeographic and macroevolutionary studies. Advances in Late Cretaceous Western Interior Basin Paleontology and Geology. Indianapolis, IN: University of Indiana Press. In press.

18. Neilson RP (1986) High-resolution climatic analysis and southwest biogeography. Science 232: 27-34

19. Dickinson WR, Snyder WS (1978) The plate tectonics of the Laramide orogeny. In: Matthews VI, editor. Laramide folding associated with basement block faulting in the western United States. Boulder, CO: Geological Society of America, Memoir 151. 355-366.

20. DeCelles PG (1986) Sedimentation in a tectonically partitioned, nonmarine foreland basin: the Lower Cretaceous Kootenai Formation, southwestern Montana Geological Society of America Bulletin 97: 911-931.

21. Perry WJJ, Haley JC, Nichols DJ, Hammons PM, Ponton JD (1988) Interactions of Rocky Mountain foreland and Cordilleran thrust belt in Lima region, southwest Montana. In: Schmidt CJ, Perry WJJ, editors. Interaction of the Rocky Mountain foreland and Cordilleran thrust belt. Boulder, CO: Geological Society of America, Memoir 171. 267-290.

22. Lawton TF (2008) Laramide sedimentary basins. In: Miall AD, editor. Sedimentary Basins of the World, The sedimentary basins of the United States and Canada. Waltham, MA: Elsevier. 429-450.

23. Cerveny PF, Steidtmann JR (1993) Fission track thermochronology of the Wind River Range, Wyoming: evidence for timing and magnitude of Laramide exhumation. Tectonics 12: 77-91.

24. Crowley PD, Reiners PW, Reuter JM, Kaye GD (2002) Laramide exhumation of the Bighorn Mountains, Wyoming: an apatite (U-Th)/He thermochronology study. Geology 30: 27-30.

25. Lawton TF (1983) Late Cretaceous fluvial systems and the age of foreland uplifts in central Utah. In: Lowell JD, Gries R, editors. Rocky Mountain foreland basins and uplifts. Denver, CO: Rocky Mountain Association of Geologists. 181-199.

26. Lawton TF (1986) Fluvial systems of the Upper Cretaceous Mesaverde Group and Paleocene North Horn Formation, central Utah: a record of transition from thin-skinned to thick-skinned deformation in the foreland region. In: Peterson JA, editor. Paleotectonics and sedimentation in the Rocky Mountain region, United States. Tulsa, OK: American Association of Petroleum Geologists, Memoir 41. 423-442.

27. Cather SM (2004) Laramide orogeny in central and northern New Mexico and southern Colorado. In: Mack GH, Giles KA, editors. The geology of New Mexico: a geologic history. Socorro, NM: New Mexico Geological Society. 203248.

28. Roberts EM (2007) Facies architecture and depositional environments of the Upper Cretaceous Kaiparowits Formation, southern Utah. Sedimentary Geology 197: 207-233. 
29. Lawton TF, Bradford BA (2011) Correlation and provenance of Upper Cretaceous (Campanian) fluvial strata, Utah, U.S.A., from zircon U-Pb geochronology and petrography. Journal of Sedimentary Research 81: 495-512.

30. Bradshaw WE, Holzapfel CM (2008) Genetic response to rapid climate change: it's seasonal timing that matters. Molecular Ecology 17: 157-166.

31. Cracraft J (1985) Biological diversification and its causes. Annals of the Missouri Botanical Garden 31: 794-822.

32. Miller AI, Mao S (1995) Association of orogenic activity with the Ordovician radiation of marine life. Geology 23: 305-308.

33. Lieberman BS, Eldredge N (1996) Trilobite biogeography in the Middle Devonian; geological processes and analytical methods. Paleobiology 22: 66-79.

34. Williams ST, Duda TFJ (2008) Did tectonic activity stimulate Oligo-Miocene speciation in the Indo-West Pacific? Evolution 62: 1618-1634

35. Badgley C (2010) Tectonics, topography, and mammalian diversity. Ecography 33: $220-231$

36. Che J, Zhou W-W, Hu J-S, Yana F, Papenfuss TJ, et al. (2010) Spiny frogs (Paini) illuminate the history of the Himalayan region and Southeast Asia. Proceedings of the National Academy of Science 107: 13765-13770.

37. Finarelli JA, Badgley C (2010) Diversity dynamics of Miocene mammals in relation to the history of tectonism and climate. Proceedings of the Royal Society B 277: 2721-2726.

38. Peters SE (2005) Geologic constraints on the macroevolutionary history of marine animals. Proceedings of the National Academy of Science 102: 1232612331.

39. Antonelli A, Nylander JAA, Persson C, Sanmartin I (2009) Tracing the impact of the Andean uplift on Neotropical plant evolution. Proceedings of the National Academy of Science 106: 9749-9754.

40. Sampson SD, Loewen MA, Farke AA, Roberts EM, Forster CA, et al. (2010) New horned dinosaurs from Utah provide evidence for intracontinental dinosaur endemism. PLoS One 5: e12292. doi:12210.11371/journal.pone.0012292.

41. Ronquist F (1996) DIVA version 1.1. Computer program and manual availabe by anonymous FTP from Uppsala University (ftp.uu.ee or ftp.systbot.uu.ee).

42. Ronquist F (1997) Dispersal-vicariance analysis: a new approach to the quantification of historical biogeography. Systematic Biology 46: 195-203.

43. Crisci JV, Katinas L, Posadas P (2003) Historical biogeography. An Introduction. Cambridge, MA: Harvard University Press.

44. Sanmartín I, Ronquist F (2004) Southern Hemisphere biogeography inferred by event-based models: plant versus animal patterns. Systematic Biology 53: 216243.

45. Chan KMA, Moore BR (2004) SYMMETREE: whole-tree analysis of differential diversification rates. Bioinformatics 21: 1709-1710.

46. Gates TA, Horner JR, Hanna RR, Nelson CR (2011) New unadorned hadrosaurine hadrosaurid (Ornithopoda: Dinosauria) from the Campanian of North America. Journal of Vertebrate Paleontology 31: 798-811.

47. Gates TA, Sampson SD (2007) A new species of Gryposaurus (Dinosauria: Hadrosauridae) from the Late Campanian Kaiparowits Formation. Zoological Journal of the Linnean Society 151: 351-376.

48. Mallon JC, Evans DC, Ryan MJ, Anderson JS (2012) Megaherbivorous dinosaur turnover in the Dinosaur Park Formation (upper Campanian) of Alberta, Canada. Palaeogeography Palaeoclimatology Palaeoecology. doi: 10.1016/ j.palaeo.2012.06.024

49. Prieto-Marquez A (2010) Global phylogeny of hadrosauridae (Dinosauria: Ornithopoda) using parsimony and Bayesian methods. Zoological Journal of the Linnean Society 159: 435-502.

50. Evans DC, Bavington R, Campione NE (2009) An unusual hadrosaurid braincase from the Dinosaur Park Formation, and the biostratigraphy of Parasaurolophus (Ornithischia: Lambeosaurinae) from southern Alberta. Canadian Journal of Earth Science 46: 791-800.

51. Evans DC, Reisz RR (2007) Anatomy and relationships of Lambeosaurus magnicristatus, a crested hadrosaurid dinosaur (Ornithischia) from the Dinosaur Park Formation, Alberta. Journal of Vertebrate Paleontology 27: 373-393.

52. Prieto-Márquez A, Chiappe LM, Joshi SH (2012) The lambeosaurine dinosaur Magnapaulia laticaudus from the Late Cretaceous of Baja California, northwestern Mexico. PloS One 7: e38207.

53. Renne PR, Fulford MM, Busby-Spera C (1991) High resolution ${ }^{40} \mathrm{Ar} /{ }^{39} \mathrm{Ar}$ chronostratigraphy of the Late Cretaceous El Gallo Formation, Baja California del Norte, Mexico. Geophysical Research Letters 18: 459-462.

54. Ostrom JH (1961) A new species of hadrosaurian dinosaur from the Cretaceous of New Mexico. Journal of Paleontology 35: 575-577.

55. Hunt AP, Lucas SG (2003) Origin and stratigraphy of historic dinosaur quarries in the Upper Cretaceous Fruitland Formation of the Fossil Forest research Natural Area, northwestern New Mexico. New Mexico Geological Society Guidebook 54: 383-388.

56. Sullivan RM, Williamson TE (1999) A new skull of Parasaurolophus (Dinosauria: Hadrosauridae) from the Kirtland Formation of New Mexico and a revision of the genus. Albuquerque, NM: New Mexico Museum of Natural History and Science. $52 \mathrm{p}$

57. Dodson P, Forster CA, Sampson SD (2004) Ceratopsidae. In: Weishampel DB, Dodson P, Osmólska H, editors. The Dinosauria, Second Edition. Berkeley, CA: University of California Press. 494-513.

58. Holdridge LR (1967) Life Zone Ecology, revised edition. San Jose, Costa Rica: Tropical Science Center. 149 p.

59. Rosenzweig M (1995) Species diversity in space and time. Cambridge, UK: Cambridge University Press.
60. Rowe RJ, Finarelli JA, Rickart EA (2010) Range dynamics of small mammals along an elevational gradient over an 80-year interval. Global Change Biology 16: 2930-2943.

61. Urban DL, O’Neill RV, Shugart HH Jr (1987) Landscape ecology. Bioscience 37: 119-127.

62. Smith T, Huston M (1989) A theory of the spatial and temporal dynamics of plant communities. Plant Ecology 83: 49-69.

63. McLachlan JS, Clark JS, Manos PS (2005) Molecular indicators of tree migration capacity under rapid climate change. Ecology 86: 2088-2098.

64. Wolfe JA, Upchurch GR Jr (1987) North American nonmarine climates and vegetation during the Late Cretaceous. Palaeogeography, Palaeoclimatology, Palaeoecology 61: 33-77.

65. Lomolino MV, Riddle BR, Brown JH (2005) Biogeography, third edition. Sunderland, MA: Sinauer Publishers. 845 p.

66. Horner JR, Weishampel DB, Forster CA (2004) Hadrosauridae. In: Weishampel DB, Dodson P, Osmólska H, editors. The Dinosauria, Second Edition. Berkeley, CA: University of California Press. 438-463.

67. Norell MA (1993) Tree-based approaches to understanding history: comments on ranks, rules, and the quality of the fossil record. American Journal of Science 293A: $407-417$

68. Scanella JB, Horner JR (2010) Torosaurus Marsh, 1891, is Triceratops Marsh, 1889 (Ceratopsidae: Chasmosaurinae): Synonymy Through Ontogeny. Journal of Vertebrate Paleontology 30: 1157-1168.

69. Johnson KR, Nichols DJ, Hartman JH (2002) Hell Creek Formation: A 2001 synthesis. In: Hartman JH, Johnson KR, Nichols DJ, editors. The Hell Creek Formation and the Cretaceous-Tertiary boundary in the northern Great Plains: An integrated continental record of the end of the Cretaceous. Boulder, CO: Geological Society of America. 503-510.

70. Campione NE, Evans DC (2011) Cranial growth and variation in edmontosaurs (Dinosauria: Hadrosauridae): Implications for latest Cretaceous megaherbivore diversity in North America. PloS One 6: 1-12.

71. Longrich NR, Field DJ (2012) Torosaurus is not Triceratops: Ontogeny in chasmosaurine ceratopsids as a case study in dinosaur taxonomy. PloS One 7: e32623.

72. Mederos S, Tikoff B, Bankey V (2005) Geometry, timing, and continuity of the Rock Springs uplift, Wyoming, and Douglas Creek arch, Colorado. Rocky Mountain Geology 40: 167-191.

73. Liu L, Gurnis M (2010) Dynamic subsidence and uplift of the Colorado Plateau. Geology 38: 663-666.

74. Horton BK, Constenius KN, DeCelles PG (2004) Tectonic control on coarsegrained foreland-basin sequences: An example from the Cordilleran foreland basin, Utah. Geology 32: 637-640.

75. Dickinson WR, Fiorillo AR, Hall DL, Monreal R, Potochnik AR, et al. (1989) Cretaceous strata of southern Arizona. In: Jenney JP, Reynolds SJ, editors. Geologic evolution of Arizona. Tucson, AZ: Arizona Geological Society Digest 17. $447-461$.

76. Lucas SG, Basabilvazo GT, Lawton TF (1990) Late Cretaceous dinosaurs from the Ringbone Formation, southwestern New Mexico. Cretaceous Research 11: $1-7$.

77. Jacques-Ayala C (1999) Stratigraphy of El Chanate Group (Late Cretaceous) and its implications for the tectonic evolution of northwestern Sonora, Mexico. Revista Mexicana de Ciencias Geologicas 16: 97-120.

78. Young JR, McMillan NJ, Lawton TF, Esser RP (2000) Volcanology, geochemistry, and structural geology of the Upper Cretaceous Hidalgo Formation, southwestern New Mexico. Guidebook 51. Socorro, NM: New Mexico Geological Society. 149-157.

79. Carr TD, Williamson TE, Britt BB, Stadtman K (2011) Evidence for high taxonomic and morphologic tyrannosaurid diversity in the Late Cretaceous (late Campanian) of the American southwest and a new short-skulled tyrannosaurid from the Kaiparowits Formation of Utah. Naturwissenschaften 98: 241-246.

80. Zanno LE, Varricchio DJ, O'Connor PM, Titus AL, Knell MJ (2011) A new troodontid theropod, Talos sampsoni gen. et sp. nov., from the Upper Cretaceous Western Interior Basin of North America. PLoS ONE 6: e24487.

81. Horner JR (1989) The Mesozoic terrestrial ecosystems of Montana. Montana Geological Society 1989 Field Conference Guidebook 1: 153-162.

82. Campione N, Evans DC (2010) Cranial morphology and the diversity of Late Cretaceous edmontosaurs (Ornithischia: Hadrosauridae) from North America. Journal of Vertebrate Paleontology Abstracts with Programs 30: 69A.

83. Horner JR (1992) Cranial morphology of Prosaurolophus (Ornithischia: Hadrosauridae) with descriptions of two new hadrosaurid species and an evaluation of hadrosaurid phylogenetic relationships. Museum of the Rockies Occasional Paper 2: 1-119.

84. Gates TA, Scheetz R, Barrick R (2009) The first complete dinosaur from the Late Cretaceous Book Cliffs (Neslen Fm) of eastern Utah: identification and significance. Journal of Vertebrate Paleontology 29(3 Supp): 103A

85. Kirkland JI, Hernández-Rivera R, Gates T, Paul GS, Nesbitt S, et al. (2006) Large hadrosaurine dinosaurs from the latest Campanian of Coahuila, Mexico. In: Lucas SG, Sullivan RM, editors. Late Cretaceous Vertebrates from the Western Interior. Albuquerque, NM: New Mexico Museum of Natural History and Science. 299-315.

86. Lucas SG, Spielmann JA, Sullivan RM, Hunt AP, Gates T (2006) Anasazisaurus, a hadrosaurian dinosaur from the Upper Cretaceous of New Mexico. In: Lucas SG, Sullivan RM, editors. Late Cretaceous Vertebrates from the Western 
Interior. Albuquerque, NM: New Mexico Museum of Natural History and Science. 293-297.

87. Bell PR (2011) Redescription of the skull of Saurolophus osborni Brown 1912 (Ornithischia: Hadrosauridae). Cretaceous Research 32: 30-44.
88. Wagner JR (2001) The hadrosaurian dinosaurs (Ornithischia: Hadrosauria) of Big Bend National Park, Brewster County, Texas, with implications for Late Cretaceous paleozoogeography. Unpublished Masters Thesis: Texas Tech University. 417 p. 